\title{
Two-state irreversible thermal denaturation of muscle creatine kinase
}

\author{
Arkadii E. Lyubarev ${ }^{\mathrm{a}, *}$, Boris I. Kurganov ${ }^{\mathrm{a}}$, Viktor N. Orlov ${ }^{\mathrm{b}}$, \\ Hai-Meng Zhou ${ }^{\mathrm{c}}$ \\ ${ }^{a}$ Bach Institute of Biochemistry, Russian Academy of Sciences, Leninsky prosp. 33, Moscow 117071, Russia \\ ${ }^{\mathrm{b}}$ Belozersky Institute of Physico-Chemical Biology, Lomonosov Moscow State University, Moscow 119899, Russia \\ ${ }^{\mathrm{c}}$ Department of Biological Science and Biotechnology, Tsinghua University, Beijing 100084, China
}

Received 8 October 1998; received in revised form 10 February 1999; accepted 27 March 1999

\begin{abstract}
Thermal denaturation of creatine kinase from rabbit skeletal muscle has been studied by differential scanning calorimetry. The excess heat capacity vs. temperature profiles were independent of protein concentration, but strongly temperature scanning rate-dependent. It has been shown that thermal denaturation of creatine kinase satisfies the previously proposed validity criteria for the two-state irreversible model [Kurganov et al., Biophys. Chem.70 (1997) 125]. The energy activation value has been calculated to be $461.0 \pm 0.7 \mathrm{~kJ} / \mathrm{mol}$. (c) 1999 Elsevier Science B.V. All rights reserved.
\end{abstract}

Keywords: Creatine kinase; Irreversible thermal denaturation; Differential scanning calorimetry

\section{Introduction}

Creatine kinase (ATP: creatine $N$-phosphotransferase, EC 2.7.3.2) is an important enzyme in energy metabolism. It is well known that the rabbit muscle enzyme is a dimer with molecular mass of $84 \mathrm{kDa}$, consisting of two identical subunits [1]. Unfolding of the creatine kinase

\footnotetext{
* Corresponding author. Fax: + 7-095-954-2732.

E-mail address: inbio@glas.apc.org
}

molecule by SDS, urea, and guanidine hydrochloride as well as refolding of the enzyme have been studied extensively [2-6].

Thermal denaturation of proteins is being studied intensively today using differential scanning calorimetry (DSC). This method allows investigators to obtain valuable information on the thermodynamic and kinetic features of the process [7-9]. Recently, we proposed some new approaches to mathematical analysis of DSC data for proteins undergoing irreversible denaturation [10,11]. 
Thermal inactivation of three isoenzymes of human creatine kinase was studied by Malakhov et al. [12]. However, there are no data from investigations of thermal unfolding of creatine kinase using the DSC method. The present work uses the DSC method to study thermal denaturation of creatine kinase from rabbit skeletal muscle.

\section{Materials and methods}

The preparation of rabbit muscle creatine kinase was as described earlier [13]. Purified creatine kinase was homogeneous according to polyacrilamide gel electrophoresis in the presence and absence of SDS.

The concentration of creatine kinase was determined by absorbance at $280 \mathrm{~nm}$ using the absorption coefficient $A_{1 \mathrm{~cm}}^{1 \%}=8.8$ [14].

Calorimetric measurements were carried out in a differential adiabatic scanning microcalorimeter DASM-4 ('Biopribor', Russian Academy of Science, Pushchino, Russia) with $0.47-\mathrm{ml}$ capillary platinum cells, interfaced with an IBM-compatible computer. Prior to the DSC experiments, all samples were dialyzed against $30 \mathrm{mM}$ Hepes$\mathrm{NaOH}$ ( $\mathrm{pH}$ 8.0). A constant pressure of 2 atm was always maintained to prevent possible degassing of the samples on heating. The DSC curves were obtained by scanning the solution of creatine kinase in $30 \mathrm{mM}$ Hepes- $\mathrm{NaOH}(\mathrm{pH}$ 8.0) at temperatures from 10 to $100^{\circ} \mathrm{C}$.

Reversibility of the thermal transition was checked by reheating the samples after cooling from the first scan. Since all thermal transitions were always found to be completely irreversible, the calorimetric traces were corrected for the instrumental baseline by subtracting scans from the reheating of the samples.

The chemical baseline was subtracted using the procedure of Takahashi and Sturtevant [15].

The theoretical curves were fitted to the experimental data using an original program for IBMcompatible computer $[10,11]$ and software 'Scientist' (MicroMath Scientific Software, USA). The correlation coefficient $r$ used as a criterion for the accuracy of fitting was calculated by the equa- tion:

$r=\sqrt{1-\sum_{i=1}^{n}\left(y_{i}-y_{i}^{\mathrm{calc}}\right)^{2} / \sum_{i=1}^{n}\left(y_{i}-y_{i}^{m}\right)^{2}}$

where $y_{i}$ and $y_{i}^{\text {calc }}$ are experimental and calculated values of a function, $y_{i}^{m}$ is the mean of experimental values of the function, $n$ is the number of points.

Both experimental and theoretical curves were built using the interval between points of $0.05 \mathrm{~K}$. For reason of convenience, points in Fig. 3 are shown using the interval of $0.15 \mathrm{~K}$.

\section{Results and discussion}

Fig. 1a shows the original DSC trace of creatine kinase obtained at a scanning rate of 1 $\mathrm{K} / \mathrm{min}$. The excess heat capacity $\left(C_{p}^{\mathrm{ex}}\right)$ vs. temperature $(T)$ profile contains an asymmetric peak (with a maximum at $54.5^{\circ} \mathrm{C}$ for this scanning rate) and a scarcely discernible knob shifted from the main peak by approximately $9^{\circ}$ towards higher temperatures. The origin of the knob remains unclear; perhaps it is associated with aggregation of the enzyme. Since the main peak and the knob are clearly separated on the calorimetric curves, only the main peak was considered in further analysis.

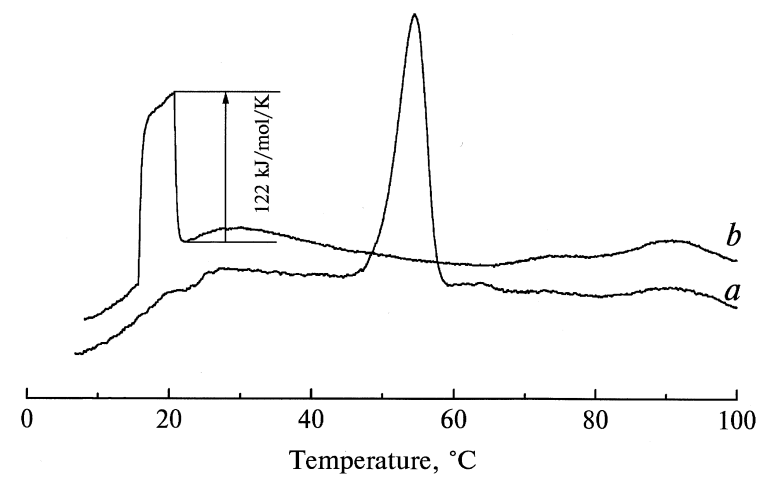

Fig. 1. DSC scan for creatine kinase (a) and reheating scan (b). Protein concentration was $2.2 \mathrm{mg} / \mathrm{ml}$, the temperature scanning rate was $1 \mathrm{~K} / \mathrm{min}$. 
When a sample of the enzyme was heated up to $100^{\circ} \mathrm{C}$ and immediately cooled, the reheating scan demonstrated no thermal effect (Fig. 1b) indicating irreversible character of the denaturation. To check whether irreversibility is caused by high temperatures, a reheating scan was carried out for the enzyme preparation which was heated up to $59^{\circ} \mathrm{C}$ (when unfolding the enzyme is completed) and then cooled to $5^{\circ} \mathrm{C}$. Again no thermal effect was observed in the area of the main peak. Moreover, after heating up to $53.5^{\circ} \mathrm{C}$ and further cooling the reheating scan showed a peak with approximately $25 \%$ enthalpy of the original peak (data not shown). Thus, we concluded, that thermal denaturation of creatine kinase was calorimetrically irreversible.

Denaturation of oligomeric proteins can include a step of reversible dissociation to monomers. In such a case, the $C_{p}^{\mathrm{ex}} v s . T$ profile becomes dependent on protein concentration owing to the bimolecular character of association [16]. The role of dissociation and association reactions in the mechanism of thermal denaturation of dimeric creatine kinase were analyzed using DSC curves at various protein concentrations. As can be seen from Fig. 2, varying the protein concentration from 0.7 to $6.5 \mathrm{mg} / \mathrm{ml}$ does not affect the shape and height of the main peak. Therefore, we can conclude that association of

$C_{\mathrm{p}}^{\mathrm{ex}}, \mathrm{kJ} / \mathrm{mol} / \mathrm{K}$

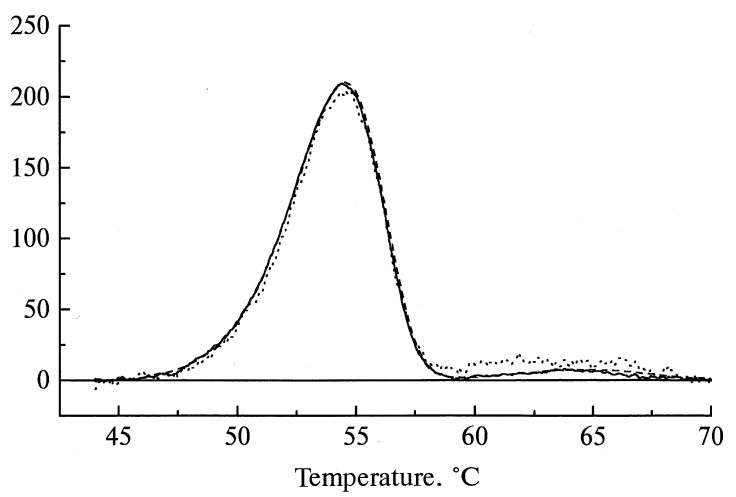

Fig. 2. Temperature dependence of excess heat capacity at various concentrations of creatine kinase: $0.7 \mathrm{mg} / \mathrm{ml}$ (dotted line), $2.2 \mathrm{mg} / \mathrm{ml}$ (solid line), $6.5 \mathrm{mg} / \mathrm{ml}$ (dashed line). The temperature scanning rate was $1 \mathrm{~K} / \mathrm{min}$.

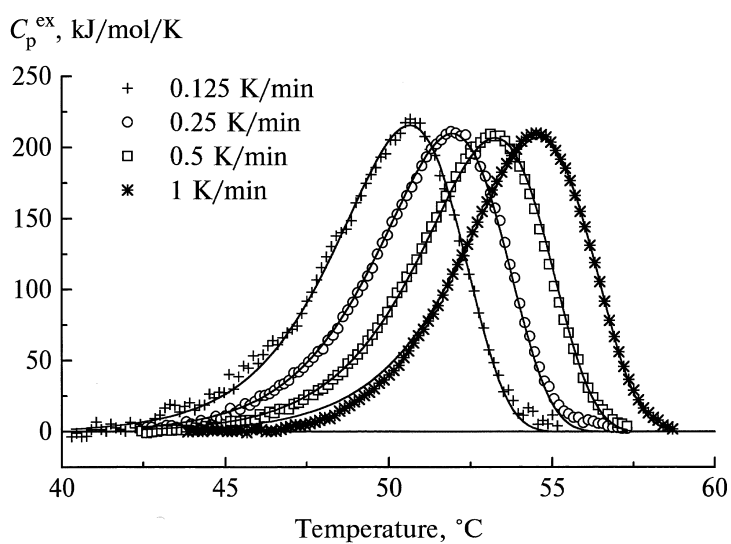

Fig. 3. Temperature dependence of excess heat capacity at the various scanning rates. The solid lines are the best fit of Eq. (4) simultaneously to all the experimental curves. Protein concentration was $2.4 \mathrm{mg} / \mathrm{ml}$.

monomers does not contribute significantly to the kinetics of the thermal denaturation of creatine kinase. It should be noted that the concentration of creatine kinase did not affect the shape of the inactivation curves [12].

The sensitivity of DSC profiles to the scanning rate is a characteristic of irreversible thermal denaturation: the maximum point is shifted towards higher temperatures as the scanning rate increases [8,9]. As can be seen from Fig. 3, the DSC curves for creatine kinase demonstrate this regularity, indicating that the process is kinetically controlled.

Sanchez-Ruiz and co-authors have proposed to use a two-state irreversible model

$N \stackrel{k}{\rightarrow} D$

( $N$ is the native protein, $D$ is the denatured state, and $k$ is the first-order rate constant) for cases of irreversible thermal denaturation under kinetic control $[8,9,17]$. It is assumed that the temperature dependence of the $k$ value follows the Arrhenius equation: $k=\exp \left\{E_{a}\left(1 / T^{*}-1 / T\right) / R\right\}$ ( $E_{a}$ is the energy of activation, $R$ is the gas constant, and $T^{*}$ is the temperature at which the rate constant equals $1 \mathrm{~min}^{-1}$ ). This model has been used for the quantitative description of thermal denaturation of some proteins [17-26]. 
Recently, we proposed a number of criteria for validity of the two-state irreversible model [10]. These criteria show that the thermal denaturation of some proteins, described with the two-state irreversible model, does not strictly follow this mechanism [10].

One of the criteria is based on the construction of the linear anamorphosis of a DSC curve in the coordinates $\left\{1 / T ; \ln \left[v C_{p}^{\mathrm{ex}} /\left(Q_{t}-Q\right)\right]\right\}$ according to the equation

$$
1 / T=1 / T^{*}-\ln \left[v C_{p}^{\mathrm{ex}} /\left(Q_{t}-Q\right)\right] /\left(E_{a} / R\right),
$$

where $v$ is the temperature scanning rate, $Q_{t}$ is the heat absorbed through the denaturation process (calorimetric enthalpy) and $Q$ is the heat absorbed during heating of the protein to the temperature $T$. If the model is valid, the points corresponding to all the scanning rates should lie on a common straight line. As can be seen from Fig. 4, this criterion is satisfactorily fulfilled for creatine kinase. The parameters of Eq. (3) determined using linear regression of the data for each scanning rate and for all the data together agree very well (data not shown).

The construction of the $\ln C_{p}^{\mathrm{ex}}$ vs. $1 / T$ plot gives another criterion. Curves obtained at various scanning rates should coincide if their maximum points are brought together. Fig. 5 shows such a graphical anamorphosis for creatine kinase. As can be seen, the curves coincide well, with only the curve corresponding to the lowest

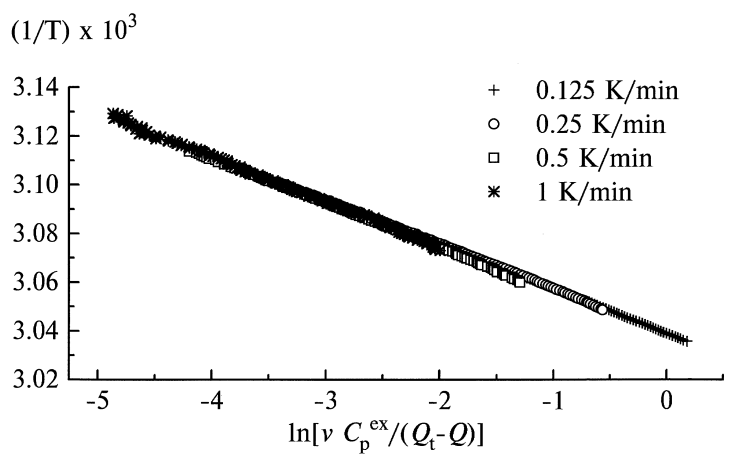

Fig. 4. The $1 / T$ value as a function of $\ln \left[v C_{p}^{\mathrm{ex}} /\left(Q_{t}-Q\right)\right]$ for creatine kinase calculated from the experimental data shown in Fig. 3.

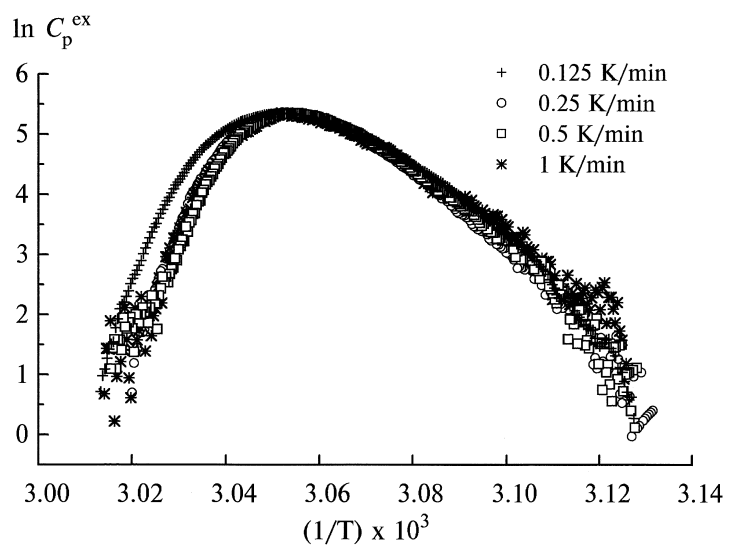

Fig. 5. Dependence of $\ln C_{p}^{\mathrm{ex}}$ on $1 / T$ for creatine kinase calculated from the experimental data shown in Fig. 3. The curves are combined in the maximum points with the corresponding dependence obtained at $v=0.125 \mathrm{~K} / \mathrm{min}$.

scanning rate deviating from the other curves in the high temperature range.

The parameters of the two-state irreversible model can be estimated by fitting the equation

$$
\begin{aligned}
C_{p}^{\mathrm{ex}}= & \frac{1}{v} Q_{t} \exp \left\{\frac{E_{a}}{R}\left(\frac{1}{T^{*}}-\frac{1}{T}\right)\right\} \\
& \times \exp \left\{-\frac{1}{v} \int_{T_{0}}^{T} \exp \left[\frac{E_{a}}{R}\left(\frac{1}{T^{*}}-\frac{1}{T}\right)\right] \mathrm{d} T\right\}
\end{aligned}
$$

to the experimental data [10]. It should be noted that Eq. (4) was obtained by solution of equation system

$$
\left\{\begin{array}{l}
\frac{\mathrm{d} \gamma_{N}}{\mathrm{~d} T}=-\frac{k \gamma_{N}}{v} \\
C_{p}^{\mathrm{ex}}=Q_{t} \frac{k \gamma_{N}}{v}
\end{array}\right.
$$

( $\gamma_{N}$ is the mole fraction of the native state). As an alternative, the fitting procedure may be carried out at once using Eq. (5).

Table 1 shows the results of fitting of Eq. (5) using the commercial software 'Scientist' to the experimental data. Fitting of Eq. (4) using a program developed earlier [10,11] gives the identical results. Close estimates of the parameters have 
Table 1

Kinetic parameter estimates for thermal denaturation of creatine kinase

\begin{tabular}{|c|c|c|c|c|c|}
\hline \multirow[t]{2}{*}{ Parameter } & \multicolumn{5}{|c|}{ Temperature scanning rate $(\mathrm{K} / \mathrm{min})$} \\
\hline & 1 & 0.5 & 0.25 & 0.125 & Fitting to all curves \\
\hline$E_{a}(\mathrm{~kJ} / \mathrm{mol})$ & $477.7 \pm 1.8$ & $463.6 \pm 1.1$ & $458.7 \pm 1.4$ & $446.0 \pm 2.5$ & $461.0 \pm 0.7$ \\
\hline$T^{*}(\mathrm{~K})$ & $328.93 \pm 0.01$ & $328.94 \pm 0.01$ & $329.09 \pm 0.02$ & $329.22 \pm 0.04$ & $329.01 \pm 0.01$ \\
\hline$Q_{t}(\mathrm{~kJ} / \mathrm{mol})$ & $1060 \pm 3$ & $1066 \pm 2$ & $1078 \pm 2$ & $1114 \pm 4$ & $1079 \pm 1$ \\
\hline$r$ & 0.9988 & 0.9995 & 0.9993 & 0.9980 & 0.9983 \\
\hline
\end{tabular}

been obtained by linear regression of the dependence of $1 / T$ on $\ln \left[v C_{p}^{\text {ex }} /\left(Q_{t}-Q\right)\right]$ (data not shown).

As can be seen from Table 1, the estimates of the energy of activation obtained for the curves corresponding to the various scanning rates, strictly speaking, do not coincide. However, these differences are not too great (in comparison with the proteins for which denaturation was analyzed in Kurganov et al. [10]). Still lower differences were obtained for the parameter $T^{*}$.

Recently, we proposed fitting a theoretical expression for the dependence of $C_{p}^{\mathrm{ex}}$ on $T$ simultaneously to all the experimental curves [11]. As can be seen from Table 1 and Fig. 3, such a fit for creatine kinase is very accurate. This is also proof of the validity of the two-state irreversible model for thermal denaturation of creatine kinase.

Thus, thermal denaturation of creatine kinase studied by the DSC method is shown to satisfy the validity criteria for the two-state irreversible model.

Since creatine kinase is a dimeric protein, one can expect that its denaturation should follow the dissociative mechanism of denaturation [16,27]:

$$
M_{2} \underset{k_{-1}}{\stackrel{k_{1}}{\rightleftharpoons}} 2 M \stackrel{k_{\mathrm{den}}}{\longrightarrow} 2 M_{\mathrm{den}}
$$

where $M_{2}$ is the native dimer, $M$ is the native monomer, $M_{\text {den }}$ is the denatured monomer, $k_{1}$ is the rate constant for dissociation of dimer, $k_{-1}$ is the rate constant for association of monomers, and $k_{\mathrm{den}}$ is the rate constant for denaturation of monomer. Nevertheless, if denaturation of monomer is rapid in comparison with dissociation of dimer and association of monomers $\left(k_{\mathrm{den}} \gg k_{1}\right.$, $k_{\text {den }} \gg k_{-1}$ ), the kinetics of denaturation of dimeric protein is formally described by the twostate mechanism [16]. In other words, the thermally induced disruption of the quarternary structure of the protein oligomer adheares kinetically to the 'all-or-not' law:

$M_{2}$ (native) $\stackrel{k}{\rightarrow} 2 M($ denatured $)$,

where $k$ is the effective rate constant for the denaturation process. Our results suggest that such a situation is realized for creatine kinase.

\section{Acknowledgements}

We are grateful to Drs N.A. Chebotareva, N.V. Fedurkina, and L.G. Mitskevich for technical assistance. The study was funded by a joint grant of the Russian Foundation for Basic Research and the State Foundation of Natural Sciences of China (Grant number 96-04-10016C) and grant of the Russian Foundation for Basic Research (Grant number 96-04-50819).

\section{References}

[1] S. Putney, W. Herlihy, N. Royal et al., J. Biol. Chem. 259 (1984) 14317.

[2] G.F. Bickerstaff, C. Paterson, N.C. Price, Biochim. Biophys. Acta 621 (1980) 305.

[3] H.M. Zhou, C.L. Tsou, Biochim. Biophys. Acta 869 (1986) 69.

[4] H.M. Zhou, X.H. Zhang, Y. Yin, C.L. Tsou, Biochem. J. 291 (1993) 103.

[5] Z.F. Wang, M.Q. Huang, X.M. Zou, H.M. Zhou, Biochim. Biophys. Acta 1251 (1995) 109.

[6] H.P. Yang, H.N. Zhong, H.M. Zhou, Biochim. Biophys. Acta 1338 (1997) 147. 
[7] P.L. Privalov, S.A. Potekhin, Methods in Enzymology, 131, Academic Press, New York, 1986, p. 4.

[8] E. Freire, W.W. van Osdol, O.L. Mayorga, J.M. Sanchez-Ruiz, Annu. Rev. Biophys. Biophys. Chem. 19 (1990) 159.

[9] J.M. Sanchez-Ruiz, in: B.B. Biswas, S. Roy (Eds.), Proteins: Structure, Function, and Engineering (Subcellular Biochemistry), 24, Plenum Press, New York, 1995, p. 133.

[10] B.I. Kurganov, A.E. Lyubarev, J.M. Sánchez-Ruiz, V.L. Shnyrov, Biophys. Chem. 69 (1997) 125.

[11] A.E. Lyubarev, B.I. Kurganov, A.A. Burlakova, V.N. Orlov, Biophys. Chem. 70 (1998) 247.

[12] V.N. Malakhov, V.A. Tischenko, I.I. Efron, E.A. Chukhriy, V.A. Isachenkov, Biokhimiya 42 (1977) 1221.

[13] Q.Z. Yao, L.X. Hou, H.M. Zhou, C.L. Tsou, Sci. Sin. (Ser. B) 25 (1982) 1186.

[14] D.C. Watts, in: P.D. Boyer (Ed.), The Enzymes, 8, Academic Press, New York, 1973, p. 383.

[15] K. Takahashi, J.M. Sturtevant, Biochemistry 20 (1981) 6185.

[16] J.M. Sanchez-Ruiz, Biophys. J. 61 (1992) 921.

[17] J.M. Sánchez-Ruiz, J.L. Lopéz-Lacomba, M. Cortijo, P.L. Mateo, Biochemistry 27 (1988) 1648.
[18] J.M. Sanchez-Ruiz, J.L. Lopez-Lacomba, P.L. Mateo, M. Vilanova, M.A. Serra, F.X. Aviles, Eur. J. Biochem. 176 (1988) 225.

[19] M. Guzmán-Casado, A. Parody-Morreale, P.L. Mateo, J.M. Sánchez-Ruiz, Eur. J. Biochem. 188 (1990) 181.

[20] P.E. Morin, D. Diggs, E. Freire, Biochemistry 29 (1990) 781.

[21] J.R. Lepock, A.M. Rodahl, C. Zhang, M.L. Heynen, B. Waters, K.-H. Cheng, Biochemistry 29 (1990) 681.

[22] F. Conejero-Lara, J.M. Sánchez-Ruiz, P.L. Mateo, F.J. Burgos, J. Vendrell, F.X. Avilés, Eur. J. Biochem. 200 (1991) 663.

[23] D.I. Kreimer, V.L. Shnyrov, E. Villar, I. Silman, L. Weiner, Protein Sci. 4 (1995) 2349.

[24] A.L. Garda-Salas, R.I. Santamaría, M.J. Marcos, G.G. Zhadan, E. Villar, V.L. Shnyrov, Biochem. Mol. Biol. Int. 38 (1996) 161.

[25] V.L. Shnyrov, M.J. Marcos, E. Villar, Biochem. Mol. Biol. Int. 39 (1996) 647.

[26] T. Vogl, C. Jatzke, H.-J. Hinz, J. Benz, R. Huber, Biochemistry 36 (1997) 1657.

[27] O.M. Poltorak, E.S. Chukhray, I.Yu. Torshin, Biochemistry (Moscow) 63 (1998) 303. 